\title{
Central haemodynamic expressions of heart failure
}

Felix Burkart

The pathophysiology of congestive heart failure is complex and many important aspects are poorly understood; hence the subject remains attractive to researchers in clinical medicine.

\section{Central haemodynamic changes in heart failure}

Heart function is determined by contractility, preload, and afterload. When cardiac output decreases, a change of reflexes and compensatory mechanisms sets in to restore a normal haemodynamic situation. The phase of cardiocirculatory compensation is characterised at rest by an almost normal global pump performance and a stabilised faster heart rate. In the compensated phase of congestive heart failure the cardiac response to exercise is usually abnormal, and the reduced cardiac output is redistributed in a characteristic way. ${ }^{1} \mathrm{~A}$ normal person performing moderate exercise distributes $70 \%-80 \%$ of the cardiac output to the exercising skeletal muscle, and vasoconstriction may occur in the renal bed, but renal flow does not decrease due to an increased perfusion pressure.

The response of the patient with moderate compensated heart failure is different, as cardiac output fails to rise normally with exercise. To compensate for the decreased stroke volume, filling pressure rises to improve contractility. This happens already in normal people with increasing age due to a loss of compliance. Therefore, filling pressures and pulmonary vascular resistance increase above the normal limit during exercise as can be seen in a series of normal people of different ages. $^{2}$

Although preload influences stroke volume in normal people, a change of the filling pressure alters stroke volume only slightly in severe heart failure. Conversely, stroke volume is largely independent of afterload in normal people whereas in patients with heart failure even slight reductions in stroke volume result in an improvement of the effective cardiac output.

Whatever led to the development of congestive heart failure, the heart and circulation have only limited means to adapt to and compensate for it. The mechanisms considered to be most effective and important are ventricular hypertrophy and neurohumoral changes.

\section{Hypertrophy}

A pressure or volume overload on the myocardium increases the wall stress of the involved ventricle and leads to hypertrophy. Although there is some controversy about what initiates hypertrophy, there is good evidence to suggest that the increased wall stress in itself, and not associated factors such as increased sympathetic stimulation, leads to hypertrophy. ${ }^{3}$

Cardiac hypertrophy is generally viewed as a compensatory process that normalises wall stress. After complete normalisation of wall stress due to increased wall thickness, hypertrophy usually stabilises. ${ }^{45}$ Pressure overload rather than volume overload generally leads to more pronounced hypertrophy.

Measurements of the contractile state of the hypertrophied myocardium have been performed on the right ventricular myocardium of animal models subjected to pressure overload. From these experiments, it was postulated that overloaded hypertrophied myocardium has an inherent defect of contractility. ${ }^{6}$ This simple view is no longer accepted. Rather, the functional consequences of cardiac overload arise from the combined result of type, degree, and duration of overload, species studied, and particularly chamber affected. Thus it has been shown that the right ventricle is particularly sensitive to pressure overload, with decreases of contractility found even before clinical failure. ${ }^{7}$ The abnormalities are still reversible until the development of overt failure. Once failure has ensued, it is no longer reversible. ${ }^{8}$ In contrast, the left ventricle seems to tolerate both pressure and volume overload for a considerable time before abnormalities of contraction can be detected. ${ }^{9}$

The differences between the functional consequences, particularly of pressure overload, between right and left ventricles are not fully understood but may be the consequence of the normal anatomical function of the ventricles. The right ventricle has been compared with a thin walled sac and the left ventricle to a thick walled pressure pump. ${ }^{10}$ Therefore, pressure overload constitutes a qualitative change for the right ventricle, but a quantitative change for the left ventricle.

Data obtained in vitro with human myocardium also lead one to question the opinion that the hypertrophied and failing heart has an intrinsic defect of contraction. Feldman et al showed in in vitro experiments that trabecular muscle from the hearts of heart transplant recipients with end stage heart failure developed the same peak isometric tension after stimulation by calcium, 
glycosides, and phosphodiesterase inhibitors as trabecular muscle from donor hearts. ${ }^{11}$ The response was less, however, for $\beta$ adrenergic stimulation by isoprenaline, or for inhibition of phosphodiesterase activity by milrinone. Data from Fowler et al also suggest similar results as the response of the left ventricle to intravenous calcium, in terms of changes in the maximal rate of rise of ventricular pressure in patients with severely depressed left ventricular function, was similar to that of patients with relatively normal left ventricular function. ${ }^{12}$ The response to $\beta$ adrenergic stimulation with dobutamine was less in patients with more advanced heart failure.

Even though the concept of depressed contractile function in the failing myocardium must be seen in a different light, several abnormalities associated with hypertrophy and failure at the myocardial and cellular level of the cardiocyte have been studied.

(a) The increased mass and work load of hypertrophied myocardium require an increased blood supply. Myocardial blood flow is usually normal at rest, but the vasodilator reserve seems to be less during stress in most forms of hypertrophy. ${ }^{1314}$

(b) One of the most consistent findings, also noted in the study by Feldman, et al in hearts from heart transplant recipients, ${ }^{11}$ is a lengthened action potential and contraction together with increased time until relaxation is complete. ${ }^{15}$ It has been argued that this may be due to increased size of the cardiocytes, which may lead to a decrease in the proportion of electrically effective cell surface for calcium entry per unit cell volume. ${ }^{16}$ Alternatively, this finding may show an inhibition of calcium uptake by, or release from, the sarcoplasmic reticulum in patients with heart failure. ${ }^{17}$

(c) The production of cyclic AMP by hypertrophied and failing cardiocytes has also received a great deal of attention. The contractile response of failing myocardium to $\beta$ adrenergic stimulation by isoprenaline is subnormal. ${ }^{112}$ As the response to direct stimulation of the catalytic unit of adenylate cyclase by forskolin remained unchanged, ${ }^{11}$ the reduced response to isoprenaline probably can be attributed to deficient $\beta$ adrenoceptor mediated cyclic AMP production. This is supported by data that show a down regulation of the number of $\beta$ adrenoceptors in the failing myocardium, ${ }^{12}$ which leads to a preponderance of the $\beta_{2}$ adrenoceptors. The failing myocardium seems to depend upon the stimulation of these to a greater degree than does normal myocardium. ${ }^{18} \mathrm{~A}$ defect of $\beta$ adrenoceptor mediated sympathetic support may be important in depressing cardiac function in human congestive heart failure.

(d) An altered myosin adenosine triphosphatase composition of the failing myocardium has been described in a rat model, ${ }^{1920}$ with a shift of the isoforms of this enzyme towards a slower, less active form. This effect seems to be species specific and is probably irrelevant in patients with heart failure, as myocardium in normal humans already contains mostly the $V_{3}$ isoform of the enzyme.

Neurohumoral changes

Activation of the sympathetic nervous system in congestive heart failure results from unloading of arterial baroreceptors by reduced blood pressure or stroke volume. Increased efferent discharge of sympathetic neurons leads to increased heart rate, contractility, and peripheral vasoconstriction. ${ }^{21-23}$ In principle these changes are appropriate for maintaining the function of vital organs; nevertheless, peripheral vasoconstriction also increases afterload with its detrimental effects on ventricular performance.

The role of the renin-angiotensin-aldosterone system has also been thoroughly studied. ${ }^{24-26}$ Increased activity of this system and stimulation of release of antidiuretic hormone through a central action of angiotensin II lead to fluid retention that is thought to improve cardiac performance by the Frank-Starling mechanism. The peripheral vasoconstrictor effects of angiotensin II also lead to peripheral vasoconstriction; similar to increased sympathetic nervous system activity, they lead to increased afterload, with its potential for further deterioration of cardiac performance. The timing of activation of the sympathetic nervous system during development of heart failure is not clear, but recent studies in animal models ${ }^{27}$ and in humans ${ }^{28}$ suggest that it may only be activated acutely and during advanced stages of heart failure. Much of the increase seen in congestive heart failure may be due to the effects of commonly described diuretics. Peripheral resistance may be directly dependent on angiotensin mediated vasoconstriction in patients with advanced disease, although in patients with milder cardiac dysfunction, vasoconstriction may be rendered dependent by treatment with diuretics.

Another humoral factor that has attracted attention is the atrial natriuretic peptide (ANP) or factor. ${ }^{29}$ This is secreted in response to atrial distention or stretch. This has been documented in normal humans undergoing water immersion ${ }^{30}$ or volume loading, ${ }^{28}$ and also in patients with acute atrial distension due to atrial fibrillation or supraventricular tachycardia. ${ }^{31}$ This stimulatory pathway also seems to operate in patients with congestive heart failure in whom plasma ANP concentrations are raised ${ }^{32}$ and directly proportional to right atrial filling pressures..$^{33}$ None the less, its role in congestive heart failure remains to be defined.

\section{Physical capacity to work}

The main symptoms that patients experience and that subjectively limit exercise capacity are pulmonary congestion, breathlessness, and muscle fatigue. Even though congestion has lent its name to the clinical syndrome, it should be recognised that this symptom is no longer as prominent ${ }^{34}$ because of the availabil- 
ity of modern drugs such as diuretics, venodilators, nitrates, or the angiotensin converting enzyme (ACE) inhibitors. Lipkin and coworkers have shown that maximal oxygen consumption as an objective measure of exercise capacity did not correlate with maximal pulmonary capillary wedge pressure during exercise even though patients stopped performing exercise in this particular test due to dyspnoea. ${ }^{35}$ Similarly, Fink and coworkers found no increase in exercise capacity in patients with congestive heart failure after acutely lowering their filling pressures either by ACE inhibition or dobutamine infusions. ${ }^{36}$ Bayliss and coworkers could not find a relation between an index of left ventricular filling pressure and exercise duration, either during control conditions or when the filling pressure was lowered chronically by captopril or prazosin. ${ }^{37}$ In contrast with acute heart failure where dyspnoea is clearly related to increased pulmonary pressure, other factors seem to influence this symptom to a large extent in chronic congestive heart failure.

\section{Drug studies for the treatment of heart failure}

One of the first studies to show the beneficial effect of glyceryl trinitrate in the treatment of heart failure due to acute myocardial infarction was the study of Chatterjee et al..$^{38}$ With a decrease in preload due to venous pooling or volume reduction, filling pressures and clinical symptoms of dyspnoea always improve, but according to the severity of congestive heart failure, stroke volume can decrease or increase. If afterload is lowered at the same time with-for example, ACE inhibitors-the decrease in filling pressure always parallels an increase in cardiac performance.

A beneficial acute effect does not guarantee a long acting change. The study of Gavazzi et al shows that with ibopamine the chronic effect is less pronounced than the acute, but is still above the control level, ${ }^{39}$ whereas with other drugs such as prenalterol, the acute effect vanishes totally after a few months. ${ }^{40} \mathrm{~A}$ similar long lasting effect on central haemodynamics was shown with prazosin, ${ }^{41}$ with hydralazine, ${ }^{42}$ or with ACE inhibition ${ }^{43}$ and may have a different impact on quality of life and prognosis as was shown in the Veterans Administration cooperative vasodilator heart failure trial (V-HeFT) studies I and $\mathrm{II}^{44}$ and in the large studies of ACE inhibition in heart failure. ${ }^{45} 46$

Substudies of the studies of left ventricular dysfunction (SOLVD) trial, where central haemodynamics are measured, show that in the treated group end diastolic volumes and pressures are decreased compared with the placebo group. These volumes slightly deteriorate in the second and third year but still show a significant difference from the control group. The pressure-volume relation curve, which is situated in heart failure to the right of normal with a decreased stroke volume, is shifted in the control group further to the right whereas in the enalapril it is returned towards normality with an increase in stroke volume. ${ }^{47}$

In conclusion, filling pressures increase with age especially during exercise in parallel with a decrease of the maximal heart rate caused by a loss of compliance of the left ventricle and the pulmonary vascular bed. In heart failure, filling pressures above normal limits, stroke volume, and changes in peripheral resistance are still important variables as are end diastolic and end systolic volumes. In studies where heart failure is being investigated, drug treatment should not only improve the acute haemodynamic situation, but also be efficient in the long term. As well as central haemodynamic changes the changes of the peripheral circulation, hormonal state, quality of life, and finally prognosis are needed to fully evaluate new drug regimens in patients with heart failure.

1 Flaim SF, Minteer WY. Ventricular volume overload alters cardiac output distribution in rats during exercise. f Appl Physiol 1980;49:482-90.

2 Ehrsam RE, Perruchoud A, Burkart F, et al. Influence of age on pulmonary hemodynamics at rest and during age on pulmonary hemodynamics at rest

3 Cooper G, Kent RL, Ubon CE, Thompson EW, Marino TA. Hemodynamic versus adrenergic control of cat righ ventricular hypertrophy. $\mathcal{F}$ Clin Invest 1985;75:1403-14.

4 Bürger SB, Strauer BE. Left ventricular hypertrophy in chronic pressure load due to spontaneous essential hypertension. Left ventricular function, left ventricula geometry, wall stress. In: Strauer BE, ed. The heart in hypertension. Berlin: Springer Verlag, 1981:13-36.

5 Meerson FZ. The myocardium in hyperfunction, hypertrophy and heart failure. Circ Res 1969;25:1-16.

6 Spann JF Jr. Heart failure and ventricular hypertrophy: altered cardiac contractility and compensatory mechanisms. Am $\mathcal{F}$ Cardiol 1969;23:504-9.

7 Cooper G, Savata R, Harrison C, Coleman HN. Mechanisms for the abnormal energetics of pressureinduced hypertrophy of cat myocardium. Circ Res 1973;33:213-23.

8 Cooper G, Marino TA. Complete reversibility of cat right ventricular chronic progressive pressure overload. Circ Res 1984;54:323-31.

9 Serizawa T, Mirsky I, Carabello B, Alpert NR. Diastolic myocardial stiffness in gradually developing left ventricular hypertrophy in dog. Am ₹ Physiol 1982;242:H633-7.

10 Cooper G. Cardiocyte adaptation to chronically altered load. Annu Rev Physiol 1987;49:501-18.

11 Feldman MD, Copelas L, Gwathmay JK, et al. Deficien production of cAMP: Pharmacological evidence of an mportant cause of contractile dysfunction in patients with end-stage heart failure. Circulation 1987;75:331-9.

12 Fowler MB, Laser JA, Hopkins GL, Minobe W, Bristow MW. Assessment of the beta-adrenergic pathway in the intact failing human heart: progressive receptor in the intact failing human heart: progressive receptor down-
Circulation and subsensibility to agonist response.

13 Bache RJ, Vrobel TR, Ring WS, Emergy RW, Anderson RW. Regional myocardial blood flow during exercise in dogs with chronic left ventricular hypertrophy. Circ Res dogs with chron.

14 Wusten B, Buss DD, Heist H, Schaper W. Dilatory capacity of the coronary circulation and its correlation to the arterial vasculature in the canine left ventricle. Basic Res Cardiol 1977;72:636-50.

15 Aronson RS. Characteristics of action potentials of hypertrophied myocardium from rats with renal hypertension. Circ Res 1980;47:443-54.

16 Keung ECH, Keung C, Aronson RS. Passive electrica properties of normal and hypertrophied rat myocardium. Am $\mathcal{~ P h y s i o l ~ 1 9 8 2 ; 2 4 3 : H 9 1 7 - 2 6 . ~}$

17 Sordahi LA, McCollum WB, Wood WG, Scharts A. Mitochondria and sarcoplasmic reticulum function in cardiac hypertrophy and failure. Am f Physiol 1973;224: 497-502.

18 Bristow MR, Ginsburg R, Umans V, et al. $\beta_{1}$ and $\beta_{2}$ adrenergic-receptor subpopulations in nonfailing and failing human ventricular myocardium: coupling of both receptor subtypes to muscle contraction and selective $\beta$ tor subtypes to muscle contraction and selective $\beta_{1}$ receptor downregulat

19 Lompre AM, Schwartz K, d'Albis A, et al. Myosin isoenzyme redistribution in chronic heart overload. Nature 1979;282:105-7.

20 Mercadier J, Bouveret P, Gorza L, et al. Myosin isoenzymes in normal and hypertrophied human ventricular myocardium. Circ Res 1983;53:52-62. 
21 Leimbach WN, Wallin G, Victor RG, Aylward PE, Sundlöf G, Mark AL. Direct evidence from intraneura recordings for increased central sympathetic outflow in patients with heart failure. Circulation 1986;73:913-9.

22 Hasking GJ, Esler MD, Jennings GL, Burton D, Korne $\mathrm{Pl}$. Norepinephrine spill-over to plasma in patients with congestive heart failure: evidence of increased overall and cardiorenal sympathetic activity. Circulation 1986; 73:615-21.

23 Di Bona GF. The functions of the renal nerves. Rev Physiol Biochem Pharmacol 1982;94:76-88.

24 Curtiss C, Cohn JN, Vrobel T, Franciosa JA. Role of the renin-angiotensin system in the systemic vasoconstric tion of chronic congestive heart failure. Circulation 1978; tion of chr:

25 Francis GS, Goldsmith SR, Levine B, Olivari MT, Cohn $J N$. The neurohumoral axis in congestive heart failure Ann Intern Med 1984;101:370-7.

26 Dzau VJ, Colucci WS, Hollenberg NK, Williams GH Relation of renin-angiotensin-aldosterone system to clinical state in congestive heart failure. Circulation 1981, 63:645-51.

27 Armstrong PW, Stopps TP, Ford SE, deBold AJ. Rapid ventricular pacing in the dog: pathophysiology studies of heart failure. Circulation 1986;74:1075-84.

28 Yamaji T, Ishibashi M, Takaku F. Atrial natriuretic factor in human blood. 7 Clin Invest 1985;76:1705-9.

29 DeBold AJ, Borenstein HB, Veress AT, Sonnenberg H. A rapid and potent natriuretic response to intravenous rapid and potent natriuretic response to intravenous infection of atrial

30 Gerbes AI, Arendt RM, Schnizer W, et al. Regulation of atrial natriuretic factor release in man: effect of wate immersion. Klinische Wochenschrift 1986;64:666-7.

31 Yamaji $T$, Ishibashi $M$, Nakaoka $H$, Imataka $K$, Amono $M$, Fujii J. Possible role for natriuretic peptide in polyuria associated with paroxysmal atrial arrhythmias [letter]. Lancet 1985;i:1211.

32 Shenker Y, Sider RS, Ostafin EA, Grekin RJ. Plasma levels of immunoreactive atrial natriuretic factor in health subjects and patients with edema. 7 Clin Invest 1985, 76:1684-7.

33 Raine AEG, Erne P, Bürgisser E, et al. Atrial natriuretic peptide and atrial pressure in patients with congestive peptide and atrial pressure in patients with

34 Jafri SM, Lakier JB, Rosman HS, Goldstein S. Prevalence of congestion in chronic heart failure. Chest 1986;90: congestion
35 Lipkin DP, Canepa-Hauson $R$, Stephens MR, PooleWilson PA. Factors determining symptoms in heart failure: comparison of fast and slow exercise tests. Br Heart $\mathfrak{f}$ $1986 ; 55: 439-45$.

36 Fink LI, Wilson JR, Ferraro N. Exercise ventilation and pulmonary artery wedge pressure in chronic stable congestive heart failure. Am $\mathcal{f}$ Cardiol 1986;57:249-53.

37 Bayliss J, Canepa-Hauson R, Norell MS, Poole-Wilson PA, Sutton G. Vasodilation with captopril and prazosin in chronic heart failure. Double blind study at rest and on exercise. Br Heart $\mathcal{F}$ 1986;55:265.

38 Chatteriee $\mathrm{K}$, et al. Vasodilation therapy in AMI. Circulation 1973;48:1183.

39 Gavazzi A, Mussini A, Bramucci E. Hemodynamic evaluation during exercise tests after acute and chronic tion during exercise tests after acute and chronic failure. Arzneimittelforschung 1986;36:368-70.

40 Lambertz H, Meyer J, Erbel R. Long-term hemodynamic effects of prenalterol in patients with severe congestive heart failure. Circulation 1984;69:298-305.

41 Bertel O, Burkart F, Bühler FR. Sustained effectiveness of chronic prazosine therapy in severe chronic congestive heart failure. Am Heart $\mathcal{f} 1981 ; 101: 529-33$.

42 Mathey D, Hanrath P, Polster J, et al. Acute and chronic effects of oral hydralazine on left ventricular pump function and renal hemodynamics in chronic left heart failure. Eur Heart f 1980;1:25-9.

43 Kiowski W, Drechsler H, Meinertz T, et al. Cilazapril in congestive heart failure. A pilot study. Drugs 1991; 41(suppl 1):54-61.

44 Cohn JN, Johnson G, Zysche S, et al. A comparison of enalapril with hydralazine isosorbide-dinitrate in the enalapril with hydralazine isosorbide-dinitrate in the treatment of chronic con

45 Consensus Trial Study Group. Effect of enalapril on mortality in severe congestive heart failure. Results of a cooperative north Scandinavian enalapril survival study. $N$ Engl $\mathcal{F}$ Med 1987;316:429-34.

46 SOLVD Investigators. Effect of angiotensin converting enzyme inhibition with enalapril on survival in patients with reduced left ventricular ejection fraction and congestive heart failure. Results of the treatment trial of the studies of left ventricular dysfunction. $N$ Engl f Med 1991;325:293-302

47 Konstam MA, Russo MF, Kronenberg MW, et al. Effects of the angiotensin converting enzyme inhibitor enalapril on the long-term progression of left ventricular dysfunction in patients with heart failure. Circulation 1992;86:431-8. 